\title{
ABORTION PILLS AS OVER-THE-COUNTER DRUGS- A BOON OR A CURSE
}

\author{
Manjula Srivastava ${ }^{1}$, Anjali Srivastava2, Kumari Namrata ${ }^{3}$
}

${ }_{1}^{1}$ Assistant Professor, Department of Obstetrics and Gynaecology, Mahatma Gandhi Memorial Medical College and Hospital. ${ }^{2}$ Associate Professor, Department of Obstetrics and Gynaecology, Mahatma Gandhi Memorial Medical College and Hospital. 3Junior Resident, Department of Obstetrics and Gynaecology, Mahatma Gandhi Memorial Medical College and Hospital.

ABSTRACT
BACKGROUND
Abortion pills were meant for medical abortion through which early unwanted pregnancy are terminated safely and effectively. But
due to widespread availability and lack of proper diligence in the promotion and usage of abortion pills, self-administration of
these drugs is rampant, thereby increase in unsupervised terminations and complications which may be life-threatening.

\section{MATERIALS AND METHODS}

This is a retrospective observational study done in MGM Medical College and Hospital, Jamshedpur from November 2016 to November 2017.

\section{RESULTS}

164 patients were admitted during this period with history of self-medication of abortion pills. The most common complaint was bleeding, which was excessive (76.2\%) or irregular $(2.6 \%)$. The other complications being abdominal pain with or without bleeding, fever or non-expulsion of products of conception. The majority of population was young, below 30 years with low literacy. Incomplete abortion was seen in majority of cases (64.6\%). Surgical treatment with blood transfusion was done in most of them $(80.6 \%)$.

\section{CONCLUSION}

Medical abortion is an effective means of termination of early pregnancy, but only under medical supervision. Self-medication and over-the-counter selling of these pills should be restricted.

\section{KEYWORDS}

Abortion Pills, Pregnancy, Bleeding.

HOW TO CITE THIS ARTICLE: Srivastava M, Srivastava A, Namrata K. Abortion pills as over-the-counter drugs- a boon or a curse. J. Evolution Med. Dent. Sci. 2018;7(07):820-823, DOI: 10.14260/jemds/2018/187

\section{BACKGROUND}

Globally induced abortion- safe or unsafe, legal or illegal- is a reproductive health service that is part of the lives of women, couples and communities in both developed and developing countries. When faced with unintended pregnancies, especially in contexts in which women lack access to effective family planning, induced abortion is an important part of women's reproductive health care.

Over the past decade in India, some key policy developments have contributed to improved availability, accessibility and safety of induced abortion services. These include revised regulations expanding services to primary health centres, the approval of medical abortion for terminating early pregnancies and the promotion of manual vacuum aspiration as the preferred method for early surgical abortion. The impact of these efforts has been dampened by difficulties in implementation. For example, the expansion of abortion services into lower level facilities has been uneven, leaving many districts with few public facilities that provide

'Financial or Other Competing Interest': None.

Submission 04-01-2018, Peer Review 31-01-2018,

Acceptance 06-02-2018, Published 12-02-2018.

Corresponding Author:

Dr. Manjula Srivastava,

Duplex-12, Vasundara estate, $\mathrm{NH}-33$,

Near Irrigation Colony, Dinms,

Jamshedpur-531018.

E-mail: manjulasrivastava78@gmail.com

DOI: $10.14260 /$ jemds $/ 2018 / 187$ the services. Studies indicate that many of the largest, least developed states are disproportionately underserved by certified facilities.

Access to safe abortion services are the need of the current era, especially when 328 million women in India are in the reproductive age group (15 - 49 years), which constitute $26 \%$ of the total population of nearly 1.2 billion.(1) Approximately, $50 \%$ of the Indian population is below 25 years of age and more than $65 \%$ below 35 years.(2) The exact number of abortions conducted in India is not known, but it is estimated that nearly 6.7 million abortions are carried out every year and $8 \%-20 \%$ of all maternal deaths are due to unsafe abortion.(3) Of this, only one million are being carried out legally.(4)

WHO has laid down specific guidelines for safe abortions. WHO guidelines indicate the necessity of pre-abortion care for women requesting abortion to confirm pregnancy, to estimate the correct gestational age and to localise the site of pregnancy as either intra- or extra-uterine. Medical abortion is restricted for use in the early first trimester (upto 63 days), the dose being $200 \mathrm{mg}$ of Mifepristone (oral) followed by 400 mcg of Misoprostol after 48 hours vaginally or orally for $<49$ days. Between 49 - 63 days, mifepristone $200 \mathrm{mg}$ orally and Misoprostol $800 \mathrm{mg}$ vaginally or orally after 48 hours is recommended. Despite all these guidelines, abortion pills are widely being sold without medical prescription by the chemist over-the-counter. Self-medication is on the rise especially in rural areas, where access to medical services is poor.(5) Such unsupervised terminations can lead to hazardous effect on the health of women. 


\section{Objectives}

This study was carried out to find the consequences of selfadministration of medical abortion pill by women to induce abortion.

\section{MATERIALS AND METHODS}

This retrospective observational study was conducted at the OB-Gynae department of MGM Medical College and Hospital, Jamshedpur. The study includes 164 women with history of self-medication with abortion pills. Self-administration means that these women did not visit any registered and trained medical practitioner or any health facility recognised to give medical abortion pill for consultation. Detailed history and examination was done, and ultrasound was done to confirm the diagnosis. The data collected included age of women, parity, marital status, literacy, gestational age at which abortion pill was taken, reason for admission to hospital, diagnosis, treatment received, need for blood transfusion and result.

\section{RESULTS}

During the study period of two years, 164 women who gave history of self-administration of medical abortion pills were admitted to our hospital with various complications.

Maximum number of patients belonged to 20 - 30 years (65.4\%) [Table 1]. Only 10 patients (5.8\%) were unmarried [Table 2]. 87 patients (53.3\%) belonged to $2^{\text {nd }}$ gravida [Table 3 ] and 83 patients (50.4\%) took abortion pills at 8 - 12 weeks of gestation [Table 5]. 76 patients $(46.3 \%)$ were illiterate (did not know to write her name or read any language) [Table 4]. 125 women (76.2\%) presented with excessive bleeding with retained product of conceptus [Table 6]. Other common presentation was pain abdomen with signs of sepsis (fever, dehydration etc.), which was in $15 \%$ of the patients. Table 7 gives diagnosis or rather outcomes following abortion pills, which suggests 106 cases (64.6\%) had incomplete abortion. 2 cases had ectopic pregnancy too. 101 patients presented with moderate anaemia, while 26 patients with haemoglobin level below 7 [Table 8]. Blood transfusion was required in $148(90 \%)$ patients. Blood transfusion was done in those requiring surgical evacuation and in severely anaemic patients. Most of the patients, 118 patients (71.5\%) required surgical evacuation and blood transfusion. Emergency laparotomy was done in 2 cases of ectopic pregnancy too [Table 9].

\section{Demography}

\begin{tabular}{|c|c|c|}
\hline Age in Years & No. of Cases & \% of Cases \\
\hline < 20 years & 34 & $20.5 \%$ \\
\hline 20-30 years & 107 & $65.4 \%$ \\
\hline$>30$ years & 23 & $14.1 \%$ \\
\hline \multicolumn{3}{|c|}{ Table 1 } \\
\hline
\end{tabular}

\begin{tabular}{|c|c|c|}
\hline Marital Status & No. of Cases & \% of Cases \\
\hline Married & 154 & $94.2 \%$ \\
\hline Unmarried & 10 & $5.8 \%$ \\
\hline \multicolumn{3}{|c|}{ Table 2 } \\
\hline
\end{tabular}

\begin{tabular}{|c|c|c|}
\hline Gravida & No. of Cases & \% of Cases \\
\hline 1 & 53 & $32.3 \%$ \\
\hline 2 & 87 & $53.3 \%$ \\
\hline$>2$ & 24 & $14.4 \%$ \\
\hline \multicolumn{3}{|c|}{ Table 3 } \\
\hline
\end{tabular}

\begin{tabular}{|c|c|c|}
\hline Education & No. of Cases & \% of Cases \\
\hline Literate & 76 & $46.3 \%$ \\
\hline Illiterate & 88 & $53.7 \%$ \\
\hline \multicolumn{3}{|c|}{ Table 4 } \\
\hline
\end{tabular}

Gestational Age at which Abortion Pills were taken

\begin{tabular}{|c|c|c|}
\hline Gestational Age & No. of Cases & \% of Cases \\
\hline$<8$ weeks & 60 & $36.3 \%$ \\
\hline 8-12 weeks & 83 & $50.4 \%$ \\
\hline$>12$ weeks & 21 & $13.3 \%$ \\
\hline \multicolumn{3}{|c|}{ Table 5 } \\
\hline
\end{tabular}

\section{Complaints}

\begin{tabular}{|c|c|c|}
\hline Complaints & No. of Cases & \% of Cases \\
\hline $\begin{array}{c}\text { Excessive bleeding with } \\
\text { retained products of conceptus }\end{array}$ & 125 & $76.2 \%$ \\
\hline $\begin{array}{c}\text { Irregular bleeding with retained } \\
\text { products of conceptus }\end{array}$ & 4 & $2.6 \%$ \\
\hline Pain abdomen & 14 & $8.8 \%$ \\
\hline $\begin{array}{c}\text { Fever with pain and irregular } \\
\text { bleeding }\end{array}$ & 15 & $9 \%$ \\
\hline $\begin{array}{c}\text { Non-expulsion products of } \\
\text { conceptus }\end{array}$ & 6 & $3.4 \%$ \\
\hline \multicolumn{2}{|c|}{ Table 6 } \\
\hline
\end{tabular}

Outcome of Abortion Pills

\begin{tabular}{|c|c|c|}
\hline Result & No. of Cases & \% of Cases \\
\hline Incomplete abortion & 106 & $64.6 \%$ \\
\hline Missed abortion & 17 & $10.4 \%$ \\
\hline $\begin{array}{c}\text { Failed abortion } \\
\text { (Live pregnancy) }\end{array}$ & 34 & $21 \%$ \\
\hline Complete abortion & 5 & $3 \%$ \\
\hline Ectopic pregnancy & 2 & $1 \%$ \\
\hline \multicolumn{3}{|c|}{ Table 7 } \\
\hline
\end{tabular}

Anaemia Classification

\begin{tabular}{|c|c|c|}
\hline Haemoglobin Levels & No. of Cases & \% of Cases \\
\hline Mild anaemia (10-11) & 37 & $22.6 \%$ \\
\hline Moderate anaemia (7-10) & 101 & $61.4 \%$ \\
\hline Severe anaemia (<7) & 26 & $16 \%$ \\
\hline \multicolumn{3}{|c|}{ Table 8 } \\
\hline
\end{tabular}

\section{Management}

\begin{tabular}{|c|c|c|}
\hline Treatment & No. of Cases & \% of Cases \\
\hline Surgical evacuation & 133 & $80.6 \%$ \\
\hline Medical methods & 24 & $14.6 \%$ \\
\hline Observation & 5 & $3 \%$ \\
\hline Laparotomy & 2 & $1 \%$ \\
\hline \multicolumn{3}{|c|}{ Table 9 } \\
\hline
\end{tabular}

\section{DISCUSSION}

WHO defines unsafe abortion as a procedure for terminating an unintended pregnancy, either by individuals without the necessary skills or in an environment that does not conform to minimum medical standards or both.(6) To decrease the incidence of unsafe abortion and thereby reduce maternal mortality ratio of country, MTP act was passed in 1971. 2002 Amendment of the MTP act legalised the use of mifepristone and misoprostol combination for termination of early pregnancy.(7) But this drug began to be used without medical consultation or without medical supervision due to over-thecounter availability and thus many untoward effects are observed in females taking these abortion pills. 
In our study $68 \%$ women were multiparous which was similar to the study by Mishra et al,(8) also reported that $78 \%$ of women who had self-administered abortion pills were multiparous. This shows that women rely on medical abortion and consider it as a better method to space the birth rather than using contraception and preventing unwanted pregnancy in the first place.

$50.4 \%$ of the patients in our study used the pills between $9-12$ weeks of gestation and another $13.3 \%$ used it after 12 weeks, which was quite alarming. This late use of abortion pills clearly shows lack of knowledge regarding the medical abortion. Here education comes into play, but more importantly education regarding medical abortion. This is because both literate and illiterate patients consumed medical abortion pills without consultation or supervision. Illiterate \% being 53.7 slightly higher than literate patients. These only shows lack of proper knowledge and education regarding abortion, be it in literate or illiterate patients. Studies indicate that the complications of second trimester medical abortion when compared with first trimester medical abortion are high with an increased risk of bleeding, sepsis and surgical evacuation. (9) Here also complications were seen more in women who had attempted second trimester abortion. Thus, it is very important to know or understand advantages and disadvantages of abortion in gestational periods.

In present study because of unsupervised medication and erratic drug schedule, $76.2 \%$ patients presented with excessive bleeding with retained products of conception. This finding corroborates with findings of Nivedita et al.(10) Signs of shock like fever, tachycardia etc. were present in $9 \%$ of cases. 8.8\% complained only of pain abdomen or abdominal discomfort. These were mainly patients of missed abortion. Non-expulsion of products of conception was found in 3.4\%. In our country where $59 \%$ of pregnant women are anaemic,(11) excessive bleeding added fuel to the fire. In present study, 26 patients were severely anaemic on presentation which required immediate blood transfusion. 101 patients were moderately anaemic. Blood transfusion was mainly done in patients requiring surgical evacuation or laparotomy which amounted to $81 \%$ of cases.

In our study $60.6 \%$ of the patients had incomplete abortion, $21 \%$ had continued live pregnancy, $10.4 \%$ had missed abortion, complete abortion in 5\% and ectopic pregnancy in $1 \% .80 .6 \%$ of cases require surgical evacuation. Ectopic pregnancy was treated with emergency laparotomy. Similar to our study, Nivedita et al(10) reported that the rate of incomplete abortion was $62.5 \%$ and failed abortion was $22.5 \%$ with $80 \%$ of these patients requiring surgical evacuation. In another study conducted by Thaker et al,(12) $70.2 \%$ patients had incomplete abortion and $10.8 \%$ had failed abortion. $15.6 \%$ were treated by medical methods and rest were observed with blood transfusion given if required.

Another complication observed was septicaemia, which was observed in 15 cases (9\%). These patients were managed with higher antibiotics and surgical evacuation.

\section{CONCLUSION}

Our hospital is one of the largest medical tertiary centres in the state of Jharkhand, which caters to large population daily. So, this study demonstrates the unwanted trend of consuming medical pills without supervision and thus exposing themselves to various complications.

This uprising trend has to be stopped and prevented from increasing, which can be done through proper knowledge first. Abortion, like most aspects of sexuality, is a taboo topic and rarely discussed. So, despite the legality of abortion in India and its provision by public facilities, most women are unaware that legal abortion services exist. At the same time, widespread media coverage and public information campaigns highlighting the illegal status of sex-determining ultrasounds and sex-selective abortions have led many women and some providers to believe that all abortions have been banned. So proper knowledge and education is a must.

Other methods have to be the supply of safe abortion services, improving the provision of safe medical abortion, addressing vulnerabilities among young and unmarried women and policy considerations. Jharkhand is a state with varying landscapes mostly located on Chota Nagpur plateau, so mainly a hilly state with mainly tribal population. These tribals have own culture and belief, so policy formulated should be made with them in mind and thus has to be acceptable to them. Here, means of transport have to be one of the basic necessities through which health services can be reached. There are a large number of villages to which access is quite difficult.

Prevention of unwanted pregnancy is the best way to prevent unsafe abortion. Every woman must be counselled regarding advantages, drawbacks, risks and limitations of different methods of abortion. Medical abortion is effective and safe when carried out under medical supervision.

Unsupervised use of medical abortion pills were associated with many complications like higher chances of incomplete abortion, failed abortion, haemorrhage leading to anaemia and needing blood transfusion, septic abortion and missed ectopic pregnancy. So over-the-counter sale of medical abortion pills should be restricted. Moreover, the need to educate women regarding the use of these drugs should be emphasised.

\section{REFERENCES}

[1] Stillman M, Frost JJ, Singh S, et al. Abortion in India: a literature review. New York: Guttmacher Institute 2014.

[2] Census India SRS Bulletin. Registrar general of India, Govt. Of India 2013.

[3] Ministry of health and family welfare, comprehensive abortion care training and service delivery guidelines, New Delhi: Government of India, 2010.

[4] Johnston HB. Abortion practice in India: a review of literature. In: Johnston HB, (eds). Working Paper, abortion assesment project. $1^{\text {st }}$ edn. Mumbai: centre for enquiry into health and allied themes (CEHAT); 2002:23.

[5] Santhya KG, Verma S. Induced abortion-the current scenario in India. In: Jejeebhoy SJ, (eds). Looking back, looking forward: a profile of sexual and reproductive health in India. Jawaharnagar, India: rawat Publications, 2004.

[6] WHO. The prevention and management of unsafe abortion. Report of a technical working group 1992. Available from: http://whqlibdoc.who.int/hq/1992/ WHO_MSM_92.5.pdf. 


\section{Jemds.com}

[7] http://ebookbrowsee.net/guidelines-formedicalabortion-in-india-doc.

[8] Mishra N. Unprecedented use of medical abortion can be injurious to health. JEMDS 2013;2(8):856-9.

[9] Mentula MJ, Niinimäki M, Suhonen S, et al. Immediate adverse events after second trimester medical termination of pregnancy: results of a nationwide registry study. Hum Reprod 2011;26(4):927-32.

\section{Original Research Article}

[10] Nivedita K, Fatima S. Is it safe to provide abortion pills over the counter? A study on outcome following selfmedication with abortion pills. J Clin Diagn Res 2015;9(1):1-4.

[11] NFHS-3 National Family health survey. http://www.nfshindia.org.

[12] Thaker RV, Deliwala KJ, Sha PT. Self-medication of abortion pill: women`s health in Jeopardy. NHLJ Med Sci 2014;3(1):26-31. 